\title{
Autophagy is a cell survival program for female germ cells in the murine ovary
}

\author{
Thomas R Gawriluk, Amber N Hale, Jodi A Flaws ${ }^{1}$, Christopher P Dillon², Douglas R Green ${ }^{2}$ \\ and Edmund B Rucker III \\ ${ }^{1}$ Department of Biology, University of Kentucky, 313 Thomas Hunt Morgan, Lexington, KY 40506, USA, ${ }^{2}$ Department \\ of Veterinary Biosciences, University of Illinois, 2001 S. Lincoln Ave., Urbana, IL 61802, USA and Department of \\ Immunology, St. Jude Children's Research Hospital, 262 Danny Thomas Place, Memphis, TN 38105, USA
}

Correspondence should be addressed to E B Rucker; Email: edmund.rucker@uky.edu

\begin{abstract}
It is estimated that infertility affects $\mathbf{1 5 - 2 0 \%}$ of couples and can arise from female or male reproductive defects. Mouse models have ascribed roles to over $\mathbf{1 0 0}$ genes in the maintenance of female fertility. Although previous models have determined roles for apoptosis in male and female fertility, we find that compromised autophagy within the perinatal ovary, through the loss of Becn1 or Atg7, results in the premature loss of female germ cells. Becn $1^{+/-}$ovaries have a $56 \%$ reduction of germ cells compared with control ovaries at post-natal day 1, whereas $\mathrm{Atg}^{-1-}$ ovaries lack discernable germ cells at this stage. Thus autophagy appears to be a cell survival mechanism to maintain the endowment of female germ cells prior to establishing primordial follicle pools in the ovary.

Reproduction (2011) 141 759-765
\end{abstract}

\section{Introduction}

Oocyte development can be classically split into six broad steps: 1) colonization of the indifferent gonad by primordial germ cells (PGCs), 2) formation of oogonia, 3) meiotic arrest at prophase I, 4) primordial follicle formation, 5) follicle maturation, and 6) ovulation (Edson et al. 2009). Early female germ cell development encompasses the first four stages and occurs during fetal and perinatal development. The fetal ovary is endowed with the greatest number of germ cells prior to entering meiotic arrest. After this stage, most female germ cell loss occurs either during the fetal/perinatal window or from post-natal follicular atresia. Ovarian follicular atresia is a cell death event that occurs in more than 99\% of mature follicles (Byskov 1978), and excessive follicular atresia is associated with premature ovarian failure, one of the most common causes of infertility in women (Anasti 1998, Matzuk \& Lamb 2008). The loss of germ cells has been attributed, in part, to genes devoted to programmed cell death (PCD).

PCD, an important physiological process required for development, is classified as type I (apoptosis), type II (autophagy), or type III (non-lysosomal vesiculate degradation). Autophagy is a conserved mechanism, from yeast to mammals, for bulk recycling of proteins and organelles (Klionsky \& Emr 2000). This process is important for normal development, tissue/organ remodeling, and cell death/survival and can be triggered under stress conditions such as nutrient deprivation. A wide array of diseases manifest from altered autophagy including neurodegenerative disorders (e.g. Alzheimer's, Parkinson's, and Huntington's diseases), liver disease, myodegenerative disorders, heart disease, inflammatory diseases, and cancer (Levine \& Kroemer 2008). Initially, the proteins/organelles are sequestered by lipids called 'isolation membranes', which then encapsulate the targets with a double-membrane structure called the autophagosome. These autophagosomes then fuse with liposomes to degrade the internal components. The yeast autophagy (Atg) proteins responsible for this process are classified into four groups: 1) induction of autophagy (ULK1 (ATG1) protein kinase complex), 2) vesicle nucleation (phosphatidylinositol 3-kinases class III (PI3KC3) lipid kinase complex), 3) vesicle expansion (ATG7-ATG12-ATG5 and GABARAPL2 (ATG8) pathways), and 4) the Atg protein retrieval system (Maiuri et al. 2007). Beclin 1 (BECN1), the mammalian counterpart of the yeast ATG6 protein, is integral in the vesicle nucleation phase for autophagosome formation. BECN1 forms a complex with u.v. radiation resistanceassociated gene (UVRAG) and BAX-interacting factor-1 (BIF1) to regulate the $\mathrm{PI} 3 \mathrm{KC} 3$ kinase complex and promote autophagosome formation (Liang et al. 2006, Takahashi et al. 2007). ATG7 is an E1-like protein that is required for the conjugation of ATG5-ATG12 and the addition of phosphatidylethanolamine to LC3/GABARAPL2 (microtubule-associated protein light chain 3). 
Previous genetic mouse models have revealed the importance of more than 20 genes that impact the germ cell populations or the establishment of primordial follicles in the murine ovary (Matzuk \& Lamb 2002, 2008). Of these, three apoptosis-associated genes are known to impact germ cell numbers in the fetalneonatal ovary: $B C l 2 / 1\left(B C l-x_{L}\right), B a x$, and caspase-2 (Bergeron et al. 1998, Rucker et al. 2000, Greenfeld et al. 2007). BCL2L1 and BAX have been shown to govern PGC numbers after colonization of the fetal gonads, around E11.5-E13.5, when a wave of apoptosis reduces the gonocyte populations. In contrast, the developmental window of germ cell loss at the time of parturition may be dependent on mechanisms other than apoptosis. Ablation of BCL2L1 in the fetal ovaries after this initial wave of germ cell loss does not impact the primordial follicle pool in the murine ovary (Riedlinger et al. 2002). Several additional reports suggest that the ovary may rely on alternative pathways of cell survival and cell death. Analysis of the mouse ovary between E19.5 and P2 revealed a $44 \%$ reduction in the number of follicles during this window (Rodrigues et al. 2009). At this stage, few germ cells or somatic cells were found to be apoptotic, whereas lysosome amplification and increased lysosomal-associated membrane protein 1 (LAMP1) expression occurred, suggesting a role for autophagy. During the germ nest breakdown and establishment of the primordial follicle pool, the germ cells may need to maintain energy homeostasis through autophagy. Autophagy can promote cell survival or lead to cell death, depending on the context (Codogno \& Meijer 2005). Therefore, we determine the effect of autophagy, through the genetic loss of Becn 1 or Atg7, on the endowment of the perinatal ovary as a pro-survival or pro-death mechanism.

\section{Results}

Characterization of mRNA from different oocyte stages was possible due to the efforts of Pan et al. (2005). They isolated oocytes from different follicle stages (primordial, primary, secondary, small antral, and large antral), extracted total RNA from each set, generated biotinylated CRNA, and hybridized probes to the 'Mouse Expression Set 430' MOE430A and MOE430B Affymetrix GeneChips (Pan et al. 2005). These arrays, which contain mouse maintenance genes as normalization controls, interrogate the expression levels of over 39000 transcripts from the mouse transcriptome. From this data set, Becn 1 mRNA was found to be expressed at highest levels in the murine ovary within the primordial oocyte (Fig. 1). With respect to stage, the highest relative expression levels were found in the primordial oocyte population (3200 avg) compared with primary (1500 avg), secondary (1500 avg), small antral (2000 avg), and large antral oocytes (1500 avg). Becn 1 mRNA expression did not differ between 1-month ovaries (4500 avg)
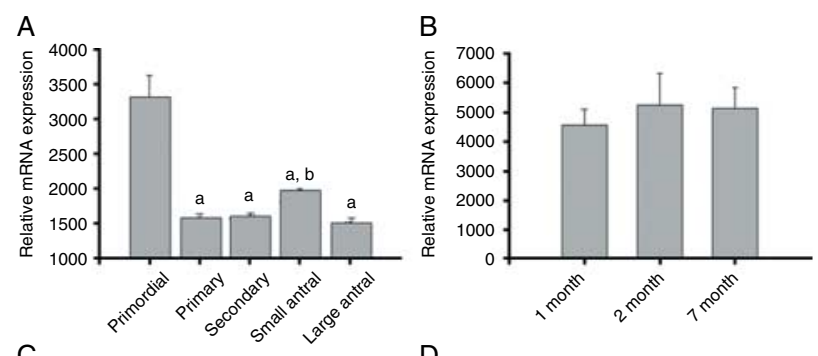

C

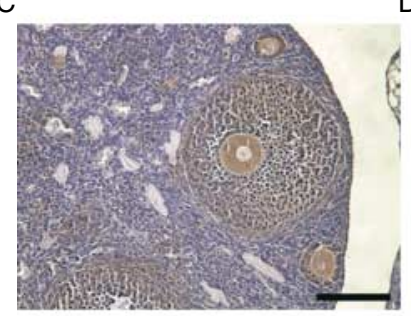

。

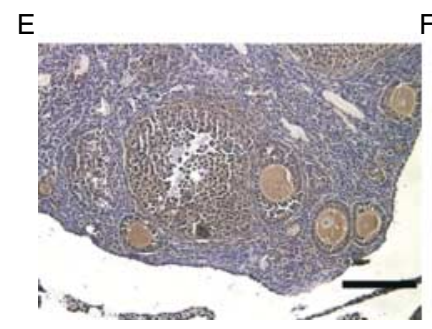

\section{$\mathrm{F}$}
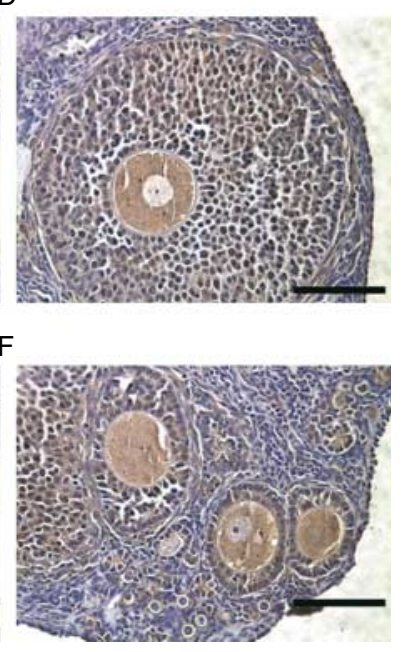

Figure 1 Expression profile of Becn $1 \mathrm{mRNA}$ and protein in the murine ovary. (A) Oocyte Becn1 mRNA expression in different stages of follicles ( $n=3$, error bar; S.E.M.; ${ }^{\text {a }} P<0.05$ compared with primordial follicles; ${ }^{b} P<0.05$ compared with primary, secondary, and antral staged follicles). (B) Ovarian Becn1 mRNA expression at different stages of development from diestrus mice ( $n=2$; error bar; S.E.M.). Figure was generated from a re-analysis of microarray data originally published by Pan et al. (2005). BECN1 immunolabeling in 3-month-old Sv129 ovary is present in all follicles (theca and granulosa cells) and oocytes, however absent from ovary epithelium. (C and E) $20 \times$ Magnification showing several follicles. (D) $40 \times$ Magnification of (B). (F) $40 \times$ Magnification of (E) showing several primordial and primary follicles. Images were taken using Nikon E800, scale bar equals $100 \mu \mathrm{M}$.

compared with 2-month (5000 avg) and 7-month ovaries (5000 avg). Atg7 mRNA expression was present at all oocyte stages from the primordial to the large antral stage but did not statistically vary (not shown). Protein analysis by immunohistochemistry revealed that BECN1 is localized to the follicle (Fig. 1). BECN1 expression is not found in the cortex or medulla, but throughout the follicle (oocyte, granulosa cells, and theca cells). As homozygous Becn1 null mice $(-/-)$ are embryonic lethal at E9.5 (Qu et al. 2003, Yue et al. 2003), we decided to examine hemizygous Becn1 ovaries (+/-) to compare them with Atg7-deficient ovaries at post-natal day 1 (P1). Analysis at this timepoint was chosen because of the perinatal lethality of ATG5- and ATG7-deficient neonates at P1 (Kuma et al. 2004, Komatsu et al. 2005). For analysis of Becn1, we generated a floxed beclin mouse model by gene targeting in embryonic stem cells, 
Table 1 Germ cell counts in post-natal day 1 murine ovaries.

\begin{tabular}{lll}
\hline Genotype of oocyte & Counts & Mean (S.E.M.) \\
\hline Becn1 $1^{+/+}$ & 10090 & $8870(962)$ \\
& 6970 & \\
Becn $1^{+/-}$ & 9550 & $4065(476)$ \\
& 4680 & \\
& 2190 & \\
& 3610 & \\
& 3830 & \\
& 4430 & \\
\hline
\end{tabular}

$\mathrm{P}<0.001$ between Becn $1^{+/+}$and Becn $1^{+/-}$.

which harbor loxP sites around exons 1 and 2. A null allele for Becn1 was generated by crossing with the MMTV-CreA line, a Cre transgenic that is expressed in the ovary for germline-specific deletions (Wagner et al. 1997). Although this transgene is 'leaky', we previously used the MMTV-CreA model to perform an oocytespecific deletion of a floxed $B C / 2 / 1$ gene because of its extremely high efficiency of recombination (Riedlinger et al. 2002).

Compromised autophagy, through loss of ATG7 or a dose-dependent reduction of $\mathrm{BECN1}$, reduces female germ cell populations in the post-natal day 1 (P1) ovaries. Morphometric analyses were performed to quantitate germ cells, similar to methods from our previous studies (Rucker et al. 2000, Borgeest et al. 2002, Riedlinger et al. 2002, Greenfeld et al. 2007). Quantitative analysis of germ cells in the $\mathrm{P} 1$ ovary revealed a BECN1-dependent reduction of germ cells (Table 1). Wild-type, control P1 ovaries had an average of 8870 germ cells (S.E.M. $=962$; $n=3$ ), compared with an average of 4065 germ cells (S.E.M. $=476 ; n=6)$ in Becn1 $1^{+/-}$hemizygous ovaries $\left(B e c n 1^{+/-}\right.$, MMTV-CreA; Becn $1^{+/-}$, or MMTV-CreA, $\left.B e c n 1^{f l /+}\right)$. There was a high loss of fetuses with the MMTV-CreA, Becn $1^{f / /}$ genotype associated with heart and brain defects at embryonic day 11.5-12.5. This was confirmed in subsequent breedings with the Ella-Cre line as well, which have mosaic Cre expression beginning at the eight-cell stage of development. From over 100 collected neonates, only two survived to the P1 stage (expected 1:4 ratio). Histological examination of the mutant P1 ovaries showed an altered distribution and a reduction in primordial follicles compared with the control ovaries (Fig. 2). Wild-type ovaries had a more uniform distribution of follicles and were larger due to the presence of more germ cells and primordial follicles. To substantiate the role of BECN1 and autophagy in the maintenance of female germ cell pools, we also collected P1 ovaries from Atg $7^{-1-}$ neonates $(n=4)$. ATG7-deficient ovaries had a loss of germ cells, and moreover, the altered appearance of the germ cells within the ovary made them impossible to quantitate (Fig. 3).

\section{Discussion}

In the context of autophagy, there are six major steps associated with the process: 1$)$ regulation of induction, 2 ) isolation membrane recruitment and vesicle nucleation, 3) vesicle elongation, 4) protein retrieval, 5) docking and fusion of autophagosome and lysosome, and 6) vesicle breakdown and degradation (Maiuri et al. 2007). BECN1 is involved with both nucleation and autophagosome maturation, whereas ATG7 is needed for vesicle elongation. Although autophagy can proceed through either ATG7-dependent or ATG7-independent pathways, our results demonstrate that female germ cells utilize both ATG7 and BECN1 for induction of autophagy for cell survival. Determination of germ cell numbers in ATG7/BECN1-deficient ovaries would clarify whether alternative pathways are utilized. Our study demonstrates that autophagy may be an important regulator of germ cell survival prior to formation of the primordial follicular pool.

In addition to this early window of germ cell loss, evidence is mounting that the atresia within the prepubertal murine ovary is dependent upon autophagy. A non-apoptotic mechanism for loss of primordial follicle pools has been highlighted in two recent studies. Atretic oocytes from P1 to P28 wild-type rat ovaries were described as having apoptotic markers of active caspase3 and positive staining for TUNEL as well as the autophagic markers of increased numbers of autophagosomes (Escobar et al. 2008a, 2008b). Of particular interest was that hallmark apoptotic characteristics, pyknotic nuclei and membrane blebbing were never observed. In the pre-pubertal mouse ovary, apoptotic characteristics (nuclear condensation, caspase 3 activation, PARP1 'poly (ADP-ribose) polymerase 1'
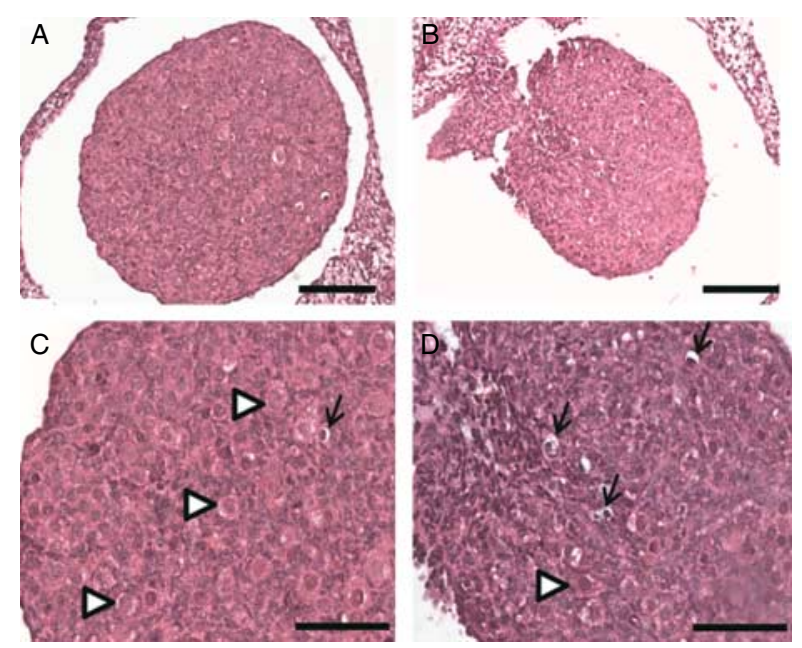

Figure 2 Reduction of germ cells in BECN1-deficient ovaries. Representative ovaries from Becn $1^{+/+}$(a and c) and Becn $1^{+/-}$females (b and d). Control ovary ( $a$ and c) shows a more uniform distribution of healthy germ cells than Becn $1^{+/-}$ovary (b and d). Arrowheads: healthy germ cells; arrows: germ cells with 'pyknotic' nuclei. Images were taken using Nikon E800, scale bar equals $100 \mu \mathrm{M}$. 


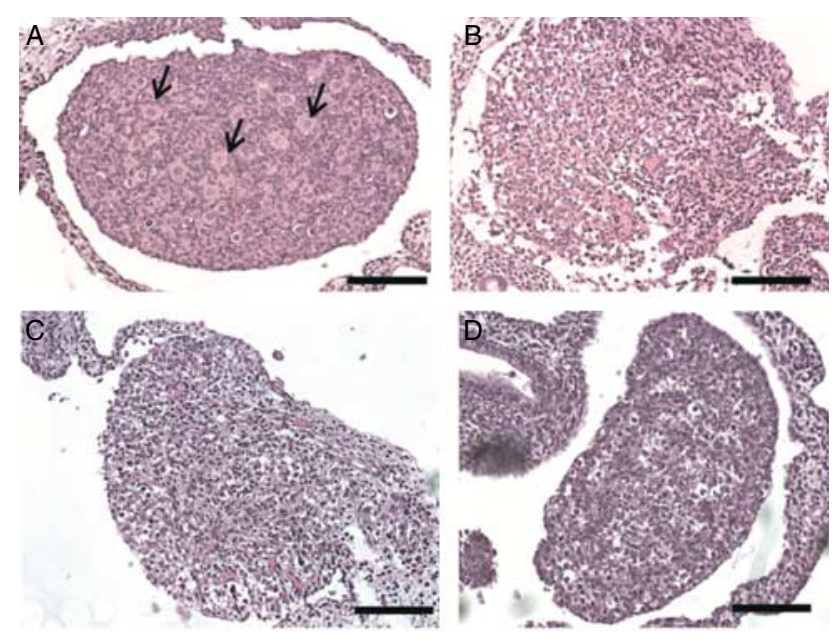

Figure 3 ATG7-deficient ovaries demonstrate loss of germ cells. (a) Postnatal day 1 (P1) control ovary contains healthy germ cells (marked by arrows). In contrast, P1 ovaries from three $\operatorname{Atg} 7^{-/-}$females show loss of distinguishable germ cells (b-d). Images were taken using Nikon E800, scale bar equals $100 \mu \mathrm{M}$.

cleavage, and DNA fragmentation) were not correlated with primordial follicles that were lost from atresia (Tingen et al. 2009). In vitro analyses of murine prepubertal oocytes showed that both apoptotic and autophagic processes were involved in the cell death of the oocytes (Lobascio et al. 2007, Escobar et al. $2008 a, 2008 b$ ). The importance of autophagy in follicular atresia has been demonstrated across multiple species including Drosophila, teleostei, caecilians, stingray, dove, quail, sheep, rats, and humans (Rosales-Torres et al. 2000, Velentzas et al. 2007, Gaytan et al. 2008, Santos et al. 2008, Zarnescu 2004).

Autophagy has been demonstrated to have a crucial function immediately after parturition within hours of birth, when neonates experience a starvation period. This is a crucial timepoint at which the neonate must utilize its energy reserves before the suckling response triggers milk ejection from the mother for sustenance. Knockout studies from Atg $5^{-1-}$ and $A \operatorname{tg} 7^{-1-}$ mice have shown a perinatal lethality (die within 1 day of birth) associated with a loss of autophagy during this early starvation period (Kuma et al. 2004, Komatsu et al. 2005). A burst of autophagy occurs upon parturition, peaks in tissues within $12 \mathrm{~h}$, and then returns to basal levels within 1-2 days. In utero, the autophagy-deficient fetuses are able to obtain metabolites through the placenta; however, amino acid levels within tissues and plasma from the neonates are reduced compared with control siblings. Thus, autophagy appears to be a requisite mechanism to maintain energy homeostasis within the neonate.

In the context of the fetal and neonatal ovary, regulation of autophagy may occur through the KIT ligand/KIT signaling pathway. Naturally occurring mutations of KIT ligand, Steel Panda $\left(S^{p a n}\right)$ and Steel
Contrasted $\left(S I^{c o n}\right)$, have been shown to result in reduced germ cell levels and fewer oocytes in the murine ovary (Huang et al. 1993, Bedell et al. 1995). Addition of anti-KIT antibody to fetal or neonatal oocytes in vitro caused a dramatic reduction in their growth (Packer et al. 1994). KIT has been localized by immunohistochemistry to female germ cells at $14 \mathrm{dpc}$ (days post-coitum) and $16 \mathrm{dpc}$, and in the oocyte in the P2 and P7 murine ovary (Kang et al. 2003). KIT signaling is traditionally known to activate the PI3K-AKT-MTOR signaling pathway to promote cell survival, and suppression of this survival pathway leads to premature follicle activation and infertility as revealed in knockout studies (Reddy et al. 2008, 2009, Adhikari et al. 2009, 2010). As MTOR acts to suppress autophagy, the question then becomes how can cells concomitantly activate AKT and autophagy pathways? This apparent contradiction may be reconciled by the notion that signaling can occur through two distinct isoforms of the PI3K p110 catalytic subunit. For AKT activation, signaling primarily occurs through the PI3K p110 $\alpha$ catalytic subunit; however, it has recently been demonstrated that the PI3K p110 $\beta$ catalytic subunit triggers autophagy through activation of the PI3K class III complex (Dou et al. 2011). A recently developed floxed PI3K p110 $\beta$ mouse model could be used to address the activation mechanism for autophagy in the developing ovary (Jia et al. 2008).

Regulation of autophagy may also occur through cross talk with apoptosis proteins, because BECN1 contains a $\mathrm{BH} 3$ region that serves as a $\mathrm{BCL} 2$ binding domain (Shimizu et al. 2004, Maiuri et al. 2007, Oberstein et al. 2007, Maiuri et al. 2010). In vitro abrogation of the BECN1-BCL2/BCL2L1 interaction with the pharmacological mimetic ABT737 triggers autophagy by reducing available BCL2/BCL2L1 (Maiuri et al. 2007). Similarly, BCl2 siRNA in MCF-7 cells induces autophagy, whereas overexpression of BCL2L1 in $\mathrm{CHO}$ cells suppressed both apoptosis and autophagy (Akar et al. 2008, Kim et al. 2009). However, BECN1 and BCL2 co-expression in HeLa cells did not demonstrate an effect of BECN1 on inhibiting the anti-apoptotic effects of BCL2 (Ciechomska et al. 2009). Although it is clear that $\mathrm{BCL} 2$ and $\mathrm{BCL} 2 \mathrm{~L} 1$ can regulate autophagy, there is some discrepancy as to the role BECN1 has on the integration of apoptotic signaling. Therefore, the susceptibility of cells to undergo apoptosis and autophagy can be linked to the free, unbound levels of the anti-apoptotic BCL2 family members. Within the developing ovary, this regulatory mechanism does not seem to be relevant. The reduction of $\mathrm{BECN} 1$ in the $\mathrm{BECN} 1^{+/-}$ovary would result in an increase in the unbound BCL2/BCL2L1 fraction, leading to a surfeit of germ cells. Since the opposite is occurring with the loss of germ cells, this suggests that autophagy is not functioning in an autophagic cell death role, but rather in a pro-survival role in the ovary. This mislabeling of autophagy as a PCD pathway seems to be a prevailing view in the scientific 
community. Currently, we are using different Cre lines to perform cell-specific deletions of Becn1 in the murine ovary to determine its role in follicle maturation and atresia. In the future, in vivo and in vitro models of atresia and premature ovarian failure should take into consideration the combined effects of apoptosis and autophagy.

\section{Materials and Methods}

\section{Gene targeting and generation of Becn1 conditional knockout mouse}

For the targeting vector, a three loxP plasmid vector (ploxP3NeoTK) with phosphoglycerol kinase (PGK)-neomycin and PGK-thymidine kinase cassettes for positive-negative selection was used. Genomic DNA isolated from 129SvEv mice was used to amplify three regions of homology for the targeting arms: a $2.7 \mathrm{~kb}$ Becn1 arm \#1 (Becn1 promoter sequence), a $3.0 \mathrm{~kb}$ Becn 1 arm \#2 (promoter, exon 1, intron 1, exon 2, and a portion of intron 2), and a $2.0 \mathrm{~kb}$ Becn 1 arm \#3 (intron 2 sequence). For the amplification, the AccuPrime Pfx was used according to manufacturer's directions to generate blunt PCR fragments that were gel purified (Gel extraction kit, Qiagen) and cloned into pBlunt vector (Invitrogen). For the electroporations, $25 \mu \mathrm{g}$ Notl-linearized DNA was resuspended in $25 \mu$ lelectroporation buffer (Chemicon, Billerica, MA, USA) and electroporated into $1 \times 10^{7} 129 \mathrm{SvEv}$ ES cells using the GenePulser II (250 V and $500 \mu \mathrm{Fd}$; Bio-Rad) with $0.4 \mathrm{~cm}$ cuvettes. G418 selection $(200 \mu \mathrm{g} / \mathrm{ml})$ was started on day 1 after electroporation and continued thereafter; ganciclovir selection $(2 \mu \mathrm{M})$ was performed on days 4-7 after electroporation. On day $12,3 \times 96$-well plates were picked and expanded for cell stocks and DNA isolation. Clones were initially screened by pooled PCRs using LaTaq (Takara) with a $5^{\prime}$-flanking reverse primer (5'-CCC TAG CTG GCC TGG AAC TCA GAA ATC T-3') and neomycin-specific reverse primer (5'-TAC CGG TGG ATG TGG AAT GTG TGC GA-3') set. The presence of the third loxP site was confirmed using flanking PCR primers (forward: 5'-CAG GAG AAG TGC CAT GGT GCA TCC TCT T-3'; reverse: 5'-CAA AGC CAA GGT TTC CAT GCT AAT GCC-3'). Individual clones were subjected to PCR confirmation from positive pools. Positive clones were confirmed by Southern blot diagnostics with an external $5^{\prime}$ probe. Targeted ES cells were expanded and used for blastocyst injections at the Transgenic Animal Core facility at Texas A\&M University.

\section{Generation of mice for ovary collections}

Beclin 'floxed' mice were generated by gene targeting in 129SvEv ES cells and will be detailed elsewhere. Becn1 null alleles were generated through heterozygous breedings of $B e c n 1^{f l n /+}$ and MMTV-CreA mice. Mice carrying homozygous floxed alleles and neomycin cassettes were confirmed by PCR of tail-snipped DNA. True floxed alleles were generated by crossing Becn1 ${ }^{f l n /+}$ and Ella-CreA mice. CreA ${ }^{+-}$Becn1 ${ }^{+/-}$ transgenic mice were generated through breeding of homozygous MMTV-CreA (Jackson Labs, 003551; Bar Harbor, ME, USA) and heterozygous Becn $1^{+/-}$mice, or those heterozygous for a 'null' Cre-generated locus. CreA strain genotypes were confirmed using Jackson Labs Protocol for Tg(MMTVCre) $1 \mathrm{Mam}$. $\mathrm{ATG}^{-1-}$ ovaries were provided by Dr Doug Green. All animal work was conducted using protocols approved by the Institutional Animal Care and Use Committee at the University of Kentucky.

\section{Histological follicle counts}

To assess follicle numbers, whole ovaries including oviduct and $\sim 1 \mathrm{~cm}$ uterus were collected from control $(n=3), B e c n 1^{+/-}$ $(n=6)$, and $\operatorname{Atg} 7^{-1-}(n=4)$ ovaries and fixed in $4 \%(\mathrm{w} / \mathrm{v})$ paraformaldehyde for at least $24 \mathrm{~h}$. After fixation, tissues were dehydrated, embedded in Paraplast (VWR International, West Chester, PA, USA), serially sectioned $(8 \mu \mathrm{m})$, mounted on glass slides, and stained with Weigert's hematoxylinpicric acid methylene blue. A stratified sample consisting of every tenth section was used to estimate total number of primordial and naked germ cells (germ cells not surrounded by somatic cells) per ovary. Only follicles with a visible nucleus were counted to avoid double counting. In addition, all follicles were counted without knowledge of the genotype of the animal.

\section{Immunohistochemistry}

Whole ovaries including oviduct and a small portion of the uterus were fixed in $4 \%(\mathrm{w} / \mathrm{v})$ paraformaldehyde for at least $24 \mathrm{~h}$. After fixation, tissues were cryo-protected by washing for $1 \mathrm{~h}$ in $10 \%$ sucrose, $1 \mathrm{~h}$ in $20 \%$ (w/v) sucrose, and at least $12 \mathrm{~h}$ in $30 \%(\mathrm{w} / \mathrm{v})$ sucrose at $4{ }^{\circ} \mathrm{C}$. Ovaries were then embedded in O.C.T. Compound (Sakura, Tokyo, Japan), frozen using a liquid nitrogen-isopentane bath, serially sectioned $(15 \mu \mathrm{m})$ and mounted on glass slides. Slides were then washed for $5 \mathrm{~min}$ with PBS and stained using ImmPRESS Reagent Kit - Anti-Rabbit IgG (Vector Labs, MP-7401; Burlingame, CA, USA) in combination with primary antibody (anti-BECN1 at 1:80 dilution (Santa Cruz, sc-11427)) overnight at $4{ }^{\circ} \mathrm{C}$. We confirmed the specificity of the antibody in control and BECN1-deficient mammary glands (WAP-Cre; $B e C n 1^{f /-}$ ) at lactation day 1. All sections were counterstained with Hematoxylin QS (Vector Labs, H-3404) and visualized using a Nikon Eclipse E400. total rabbit-lgG 1:200 dilution (Santa Cruz, sc-2027) was used as a primary antibody-negative control.

\section{Statistical analysis}

Differences in germ cell numbers were evaluated by one-way ANOVA, with statistical significance assigned at $P<0.05$. When a significant $P$ value was obtained, the Scheffe's test was used in the post hoc analysis. The SPSS (version 10; SPSS Inc., Somers, NY, USA) program was used to compile statistics from the obtained data. For microarray data, statistical analysis, ANOVA, and Holm-Sidak pairwise tests were completed with Sigma Plot (Systat, Chicago, IL, USA).

\section{Microarray data}

Becn1 mRNA expression data was obtained from microarray experiments of oocytes from primordial, primary, secondary, 
small, and large antral follicles obtained from B6SJLF1 animals. Data represents four replicates and bars $=$ S.E.M., $* P<0.05$ versus primordial, $* * P<0.05$ versus secondary/large antral. Data is obtained from previously published microarray experiments found in NCBI GEO (GDS1266 and GDS1265) (Pan et al. 2005).

\section{Declaration of interest}

The authors declare that there is no conflict of interest that could be perceived as prejudicing the impartiality of the research reported.

\section{Funding}

This research was supported by startup funds provided by the University of Kentucky to E B Rucker. C P Dillon was funded by the Sass Foundation for Medical Research.

\section{Acknowledgements}

The authors wish to thank Melissa Johnson, St Jude Children's Research Hospital Animal Imaging Center, for assistance with tissue collections.

\section{References}

Adhikari D, Flohr G, Gorre N, Shen Y, Yang H, Lundin E, Lan Z, Gambello MJ \& Liu K 2009 Disruption of Tsc2 in oocytes leads to overactivation of the entire pool of primordial follicles. Molecular Human Reproduction 15 765-770. (doi:10.1093/molehr/gap092)

Adhikari D, Zheng W, Shen Y, Gorre N, Hamalainen T, Cooney AJ, Huhtaniemi I, Lan ZJ \& Liu K 2010 Tsc/mTORC1 signaling in oocytes governs the quiescence and activation of primordial follicles. Human Molecular Genetics 19 397-410. (doi:10.1093/hmg/ddp483)

Akar U, Chaves-Reyez A, Barria M, Tari A, Sanguino A, Kondo Y, Kondo S, Arun B, Lopez-Berestein G \& Ozpolat B 2008 Silencing of Bcl-2 expression by small interfering RNA induces autophagic cell death in MCF-7 breast cancer cells. Autophagy 4 669-679.

Anasti JN 1998 Premature ovarian failure: an update. Fertility and Sterility 70 1-15. (doi:10.1016/S0015-0282(98)00099-5)

Bedell MA, Brannan CI, Evans EP, Copeland NG, Jenkins NA \& Donovan PJ 1995 DNA rearrangements located over $100 \mathrm{~kb} 5^{\prime}$ of the Steel (Sl)-coding region in Steel-panda and Steel-contrasted mice deregulate SI expression and cause female sterility by disrupting ovarian follicle development. Genes and Development 9 455-470. (doi:10.1101/gad.9.4.455)

Bergeron L, Perez GI, Macdonald G, Shi L, Sun Y, Jurisicova A, Varmuza S, Latham KE, Flaws JA, Salter JC et al. 1998 Defects in regulation of apoptosis in caspase-2-deficient mice. Genes and Development 12 1304-1314. (doi:10.1101/gad.12.9.1304)

Borgeest C, Symonds D, Mayer LP, Hoyer PB \& Flaws JA 2002 Methoxychlor may cause ovarian follicular atresia and proliferation of the ovarian epithelium in the mouse. Toxicological Sciences $\mathbf{6 8}$ 473-478. (doi:10.1093/toxsci/68.2.473)

Byskov AGS 1978 Follicular atresia. In The Vertebrate Ovary, pp 533-562. Ed. RE Jones. New York: Plenum Press.

Ciechomska IA, Goemans GC, Skepper JN \& Tolkovsky AM 2009 BCl-2 complexed with Beclin-1 maintains full anti-apoptotic function. Oncogene 28 2128-2141. (doi:10.1038/onc.2009.60)

Codogno P \& Meijer AJ 2005 Autophagy and signaling: their role in cell survival and cell death. Cell Death and Differentiation 2 1509-1518. (doi:10.1038/sj.cdd.4401751)

Dou Z, Pan JA, Lin RZ \& Zong WX 2011 The beta identity of class I Ptdlns3K: a positive role of p110 $\beta$ in autophagy revealed. Autophagy $7246-247$. (doi:10.4161/auto.7.2.14346)
Edson MA, Nagaraja AK \& Matzuk MM 2009 The mammalian ovary from genesis to revelation. Endocrine Reviews 30 624-712. (doi:10.1210/er. 2009-0012)

Escobar ML, Echeverria OM, Ortiz R \& Vazquez-Nin GH 2008a Combined apoptosis and autophagy, the process that eliminates the oocytes of atretic follicles in immature rats. Apoptosis 13 1253-1266. (doi:10.1007/ s10495-008-0248-z)

Escobar ML, Echeverría OM, Sánchez-Sánchez L, Méndez C, Pedernera E \& Vázquez-Nin GH 2008b Analysis of different cell death processes of prepubertal rat oocytes in vitro. Apoptosis 15 511-526. (doi:10.1007/ s10495-009-0448-1)

Gaytan M, Morales C, Sanchez-Criado JE \& Gaytan F 2008 Immunolocalization of beclin 1, a bcl-2-binding, autophagy-related protein, in the human ovary: possible relation to life span of corpus luteum. Cell and Tissue Research 331 509-517. (doi:10.1007/s00441-007-0531-2)

Greenfeld CR, Pepling ME, Babus JK, Furth PA \& Flaws JA 2007 BAX regulates follicular endowment in mice. Reproduction 133 865-876. (doi:10.1530/REP-06-0270)

Huang EJ, Manova K, Packer Al, Sanchez S, Bachvarova RF \& Besmer P 1993 The murine steel panda mutation affects kit ligand expression and growth of early ovarian follicles. Developmental Biology 157 100-109. (doi:10.1006/dbio.1993.1115)

Hull MG, Glazener CM, Kelly NJ, Conway DI, Foster PA, Hinton RA, Coulson C, Lambert PA, Watt EM \& Desai KM 1985 Population study of causes, treatment, and outcome of infertility. BMJ 291 1693-1697. (doi:10.1136/bmj.291.6510.1693)

Jia S, Liu Z, Zhang S, Liu P, Zhang L, Lee SH, Zhang J, Signoretti S, Loda M, Roberts TM et al. 2008 Essential roles of PI(3)K-p110beta in cell growth, metabolism and tumorigenesis. Nature 454 776-779. (doi:10.1038/ nature07091)

Kang JS, Lee CJ, Lee JM, Rha JY, Song KW \& Park MH 2003 Follicular expression of c-Kit/SCF and inhibin- $\alpha$ in mouse ovary during development. Journal of Histochemistry \& Cytochemistry 51 1447-1458. (doi:10.1177/002215540305101105)

Kim YG, Kim JY, Mohan C \& Lee GM 2009 Effect of Bcl-x(L) overexpression on apoptosis and autophagy in recombinant Chinese hamster ovary cells under nutrient-deprived condition. Biotechnology and Bioengineering 103 757-766. (doi:10.1002/bit.22298)

Klionsky DJ \& Emr SD 2000 Autophagy as a regulated pathway of cellular degradation. Science 290 1717-1721. (doi:10.1126/science.290.5497.1717)

Komatsu M, Waguri S, Ueno T, Iwata J, Murata S, Tanida I, Ezaki J, Mizushima N, Ohsumi Y, Uchiyama Y et al. 2005 Impairment of starvation-induced and constitutive autophagy in Atg7-deficient mice. Journal of Cell Biology 169 425-434. (doi:10.1083/jcb.200412022)

Kuma A, Hatano $M$, Matsui $M$, Yamamoto A, Nakaya H, Yoshimori T, Ohsumi Y, Tokuhisa T \& Mizushima N 2004 The role of autophagy during the early neonatal starvation period. Nature 432 1032-1036. (doi:10.1038/nature03029)

Levine B \& Kroemer G 2008 Autophagy in the pathogenesis of disease. Cell 132 27-42. (doi:10.1016/j.cell.2007.12.018)

Liang C, Feng P, Ku B, Dotan I, Canaani D, Oh BH \& Jung JU 2006 Autophagic and tumour suppressor activity of a novel Beclin1-binding protein UVRAG. Nature Cell Biology 8 688-699. (doi:10.1038/ncb1426)

Lobascio AM, Klinger FG, Scaldaferri ML, Farini D \& De Felici M 2007 Analysis of programmed cell death in mouse fetal oocytes. Reproduction 134 241-252. (doi:10.1530/REP-07-0141)

Maiuri MC, Le Toumelin G, Criollo A, Rain JC, Gautier F, Juin P, Tasdemir E, Pierron G, Troulinaki K, Tavernarakis N et al. 2007 Functional and physical interaction between $\mathrm{Bcl}-\mathrm{X}(\mathrm{L})$ and a BH3-like domain in Beclin1. EMBO Journal 26 2527-2539. (doi:10.1038/sj.emboj.7601689)

Maiuri MC, Criollo A \& Kroemer G 2010 Crosstalk between apoptosis and autophagy within the Beclin 1 interactome. EMBO Journal 29 515-516. (doi:10.1038/emboj.2009.377)

Matzuk MM \& Lamb DJ 2002 Genetic dissection of mammalian fertility pathways. Nature Cell Biology 4 41-49. (doi:10.1038/ncb-nm-fertilityS41)

Matzuk MM \& Lamb DJ 2008 The biology of infertility: research advances and clinical challenges. Nature Medicine 14 1197-1213. (doi:10.1038/ nm.f.1895)

Oberstein A, Jeffrey PD \& Shi Y 2007 Crystal structure of the Bcl-XL-Beclin 1 peptide complex: Beclin 1 is a novel BH3-only protein. Journal of Biological Chemistry 282 13123-13132. (doi:10.1074/jbc.M700 492200) 
Packer AI, Hsu YC, Besmer P \& Bachvarova RF 1994 The ligand of the c-kit receptor promotes oocyte growth. Developmental Biology 161 194-205. (doi:10.1006/dbio.1994.1020)

Pan H, O'Brien MJ, Wigglesworth K, Eppig JJ \& Schultz RM 2005 Transcript profiling during mouse oocyte development and the effect of gonadotropin priming and development in vitro. Developmental Biology 286 493-506. (doi:10.1016/j.ydbio.2005.08.023)

Qu X, Yu J, Bhagat G, Furuya N, Hibshoosh H, Troxel A, Rosen J, Eskelinen EL, Mizushima N, Ohsumi Y et al. 2003 Promotion of tumorigenesis by heterozygous disruption of the beclin 1 autophagy gene. Journal of Clinical Investigation 112 1809-1820. (doi:10.1172/ JCI20039)

Reddy P, Liu L, Adhikari D, Jagarlamudi K, Rajareddy S, Shen Y, Du C, Tang W, Hamalainen T \& Peng SL 2008 Oocyte-specific deletion of Pten causes premature activation of the primordial follicle pool. Science 319 611-613. (doi:10.1126/science.1152257)

Reddy P, Adhikari D, Zheng W, Liang S, Hamalainen T, Tohonen V, Ogawa W, Noda T, Volarevic S \& Huhtaniemi I 2009 PDK1 signaling in oocytes controls reproductive aging and lifespan by manipulating the survival of primordial follicles. Human Molecular Genetics 18 2813-2824. (doi:10.1093/hmg/ddp217)

Riedlinger G, Okagaki R, Wagner KU, Rucker EB III, Oka T, Miyoshi K, Flaws JA \& Hennighausen L 2002 Bcl-x is not required for maintenance of follicles and corpus luteum in the postnatal mouse ovary. Biology of Reproduction 66 438-444. (doi:10.1095/biolreprod66.2.438)

Rodrigues P, Limback D, McGinnis LK, Plancha CE \& Albertini DF 2009 Multiple mechanisms of germ cell loss in the perinatal mouse ovary. Reproduction 137 709-720. (doi:10.1530/REP-08-0203)

Rosales-Torres AM, Avalos-Rodríguez A, Vergara-Onofre $M$, HernándezPérez O, Ballesteros LM, García-Macedo R, Ortíz-Navarrete V \& Rosado A 2000 Multiparametric study of atresia in ewe antral follicles: histology, flow cytometry, internucleosomal DNA fragmentation, and lysosomal enzyme activities in granulosa cells and follicular fluid. Molecular Reproduction and Development 55 270-281. (doi:10.1002/ (SICI)1098-2795(200003)55:3 <270::AID-MRD5>3.0.CO;2-H)

Rucker EB III, Dierisseau P, Wagner KU, Garrett L, Wynshaw-Boris A, Flaws JA \& Hennighausen L 2000 Bcl-x and Bax regulate mouse primordial germ cell survival and apoptosis during embryogenesis. Molecular Endocrinology 14 1038-1052. (doi:10.1210/me.14.7.1038)
Santos HB, Thomé RG, Arantes FP, Sato Y, Bazzoli N \& Rizzo E 2008 Ovarian follicular atresia is mediated by heterophagy, autophagy, and apoptosis in Prochilodus argenteus and Leporinus taeniatus (Teleostei: Characiformes). Theriogenology 70 1449-1460. (doi:10.1016/j.theriogenology.2008.06.091)

Shimizu S, Kanaseki T, Mizushima N, Mizuta T, Arakawa-Kobayashi S, Thompson CB \& Tsujimoto Y 2004 Role of Bcl-2 family proteins in a nonapoptotic programmed cell death dependent on autophagy genes. Nature Cell Biology 6 1221-1228. (doi:10.1038/ncb1192)

Takahashi Y, Coppola D, Matsushita N, Cualing HD, Sun M, Sato Y, Liang C, Jung JU, Cheng JQ, Mulé JJ et al. 2007 Bif-1 interacts with Beclin 1 through UVRAG and regulates autophagy and tumorigenesis. Nature Cell Biology 9 1142-1151. (doi:10.1038/ncb1634)

Tingen CM, Bristol-Gould SK, Kiesewetter SE, Wellington JT, Shea L \& Woodruff TK 2009 Prepubertal primordial follicle loss in mice is not due to classical apoptotic pathways. Biology of Reproduction 81 16-25. (doi:10.1095/biolreprod.108.074898)

Velentzas AD, Nezis IP, Stravopodis DJ, Papassideri IS \& Margaritis LH 2007 Mechanisms of programmed cell death during oogenesis in Drosophila virilis. Cell and Tissue Research 327 399-414. (doi:10. 1007/s00441-006-0298-x)

Wagner KU, Wall RJ, St-Onge L, Gruss P, Garrett L, Wynshaw-Boris A, Li M, Furth PA \& Hennighausen L 1997 Cre mediated gene deletion in the mammary gland. Nucleic Acids Research 25 4323-4330. (doi:10. 1093/nar/25.21.4323)

Yue Z, Jin S, Yang C, Levine AJ \& Heintz N 2003 Beclin 1, an autophagy gene essential for early embryonic development, is a haploinsufficient tumor suppressor. PNAS 100 15077-15082. (doi:10.1073/pnas. 2436255100)

Zarnescu O 2004 Ultrastructural observations of previtellogenic ovarian follicles of dove. Zygote 12 285-292. (doi:10.1017/S0967199404002837)

Received 29 November 2010

First decision 14 January 2011

Revised manuscript received 24 February 2011

Accepted 1 April 2011 